\title{
A young man with progressive worsening dyspnoea
}

Sahan P Semasinghe Bandaralage,

Krishna Bajee Sriram

\section{CASE}

A man aged 35 years with a 14-pack year history of smoking presented to his general practitioner with a 12-month history of progressive dyspnoea. Physical examination revealed finger clubbing and bilateral upper lobe fine inspiratory crackles. Chest X-ray (CXR) showed micronodular opacification in the mid zones, extensive upper lobe fibrocystic change, superior displacement of the hila and a small left pneumothorax (Figure 1).

\section{Question 1}

What are the differential diagnoses for this patient?

\section{Question 2}

What further clinical information can assist in the diagnosis?

\section{Answer 1}

The patient's CXR findings suggest that the dyspnoea is probably due to interstitial lung disease (ILD). Lung cancer is deemed less likely given the protracted nature of symptoms and CXR findings of bilateral fibrocystic change.

\section{Answer 2}

Finding out the patient's occupational history can assist in the diagnosis. Some occupations can induce and exacerbate respiratory disorders, including ILD.
One approach to obtaining a complete occupational history is for the patient to systematically write out a list of all occupations undertaken and dust exposures during each job.

Hoy and Brims suggest four broad categories of occupational ILD:

- pneumoconiosis (eg silicosis, coal workers pneumoconiosis, asbestosis)

- hypersensitivity pneumonitis (eg farmer's lung, bird fancier's lung, mushroom worker's lung)

- granulomatous lung disease (eg berylliosis)

- other interstitial disorders (eg textile worker's lung). ${ }^{1}$

Table 1 is a summary of the three most common occupational pneumoconioses in Australia.

\section{CASE CONTINUED}

The patient had been working as a stonemason for the past 10 years, constructing and installing kitchen and bathroom tabletops (crystalline silica) without respiratory protection.

\section{Question 3}

Which investigation(s) should you order next?

\section{Answer 3}

The next investigation should be high-resolution computed tomography (HRCT) of the chest.

Also consider:

- anti-nuclear antibodies (ANAs), extractable nuclear antibodies, creatine kinase, rheumatoid factor, anti-citrullinated protein antibodies and anti-neutrophil cytoplasmic autoantibodies (ANCAs), to exclude autoimmune disease

- pulmonary function tests

- full blood count: peripheral eosinophilia (eosinophilic pneumonias)

- liver function and renal function: derangement may suggest a multisystem process (vasculitis).

\section{CASE CONTINUED}

The patient's HRCT scan is shown and described in Figure 2. Full blood count, biochemistry, ANA and ANCA serology were within normal limits. Pulmonary function tests showed an obstructive defect (forced expiratory volume in 1 second: $31 \%$ predicted, forced vital capacity: $68 \%$ predicted, and diffusion capacity of $32 \%)$.

\section{Question 4}

What is the diagnosis?

\section{Question 5}

What is the management and prognosis of this condition?

\section{Answer 4}

The diagnosis is chronic silicosis with progressive massive fibrosis (PMF). Inhalation of free crystalline silica (ie quartz, cristobalite and tridymite) can result in a spectrum of pulmonary diseases broadly referred to as 'silicosis'. The disorder can sometimes be progressive despite cessation of silica exposure. Currently there are no effective treatments for silicosis. ${ }^{2}$ Recently, the construction of engineered stone kitchen and bathroom benchtops has been 
identified as an 'at risk' occupation for the development of silicosis. ${ }^{3}$ Silicosis-related deaths are still reported in developing and developed countries, despite legally enforceable exposure limits. Around 6.4\% of Australian workers, 23 million workers in China and two million workers in the US are still being exposed to silica. ${ }^{2,4-6}$

A diagnosis of silicosis must meet the following conditions:

- history of silica exposure

- chest imaging consistent with silicosis

- lack of alternative diagnoses that better account for clinical and radiographic findings.

Typical radiological features of silicosis include upper and mid-zone nodules, which may coalesce. PMF is observed in chronic silicosis and is radiographically characterised by large confluent opacities $>1 \mathrm{~cm}$ in size with surrounding paracicatricial emphysema and radiating bands with a predilection to the upper lobes and tendency to occur bilaterally ('angel's wings'). PMF can be complicated by secondary spontaneous pneumothorax. ${ }^{2}$ Lung biopsy is usually not necessary if these conditions are met.

Pulmonary function test results in chronic silicosis can be variable. If the underlying pathology is due to fibrosis, then a restrictive defect is obvious.

However, it is now recognised that chronic silicosis can also result in emphysema, resulting in an obstructive defect, as was the case in this patient.

\section{Answer 5}

Management of chronic silicosis with PMF involves cessation of exposure to silica particles in conjunction with best supportive care to minimise respiratory morbidity (eg smoking cessation and bronchodilators for airflow limitation). Patients with silicosis are at increased

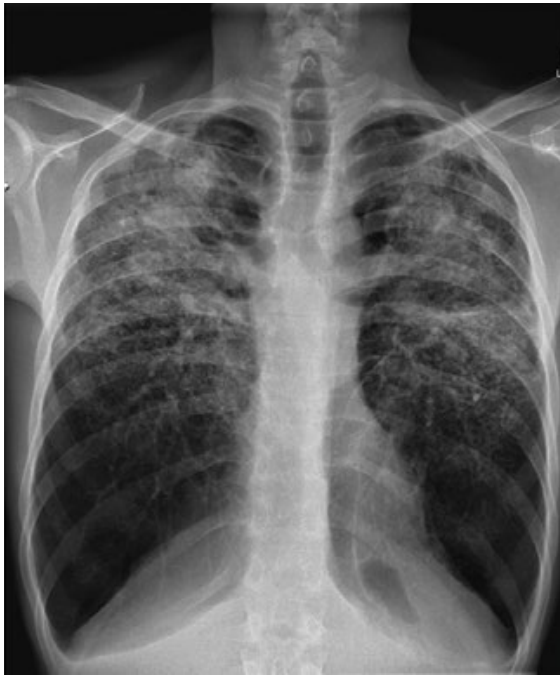

Figure 1. Chest $X$-ray showing bilateral micronodular opacification in the mid zones, upper lobe fibrocystic change, alveolar opacification in the upper zones and small left pneumothorax.

Table 1. Overview of common occupational pneumoconioses in Australia

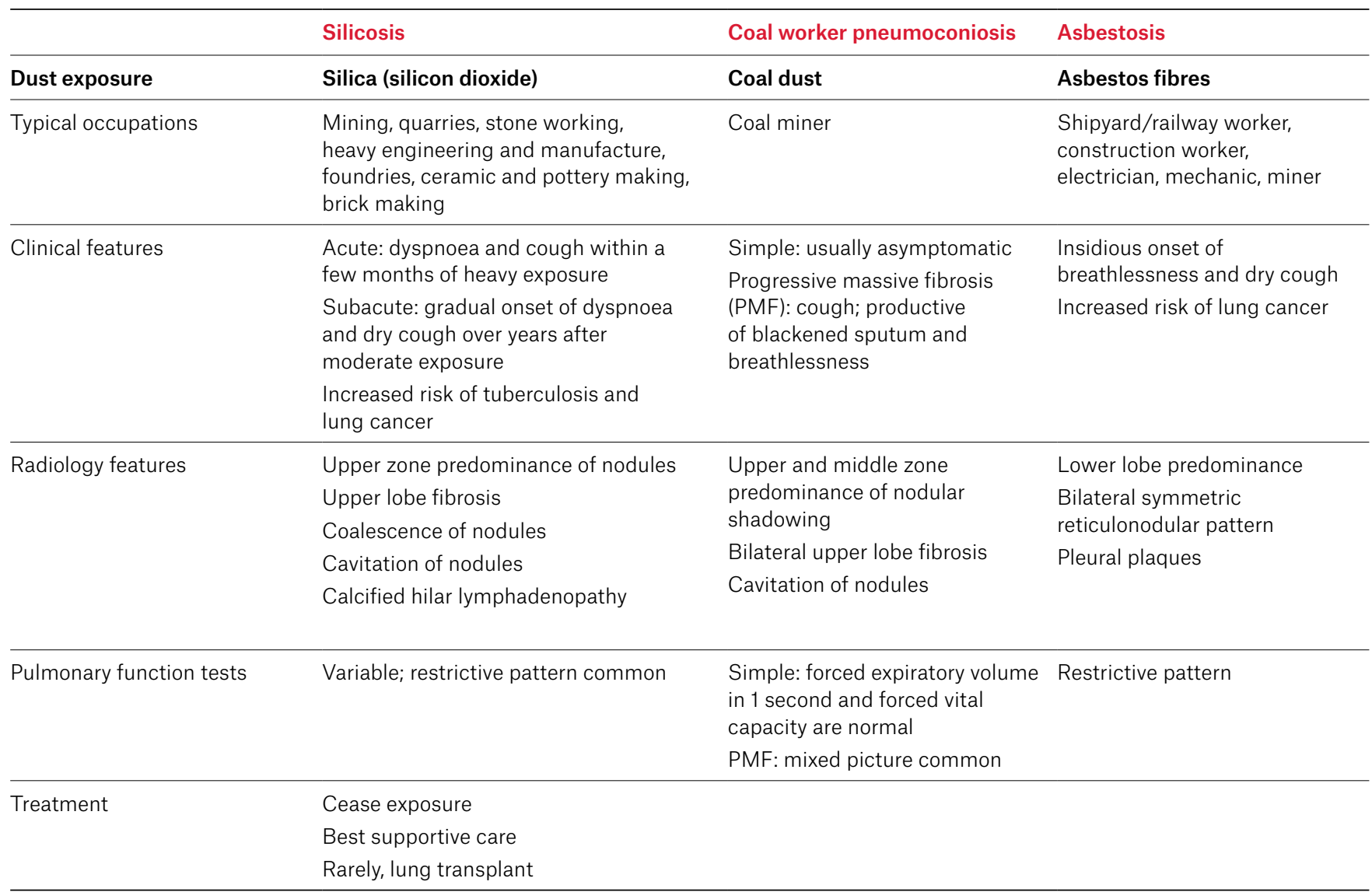


risk of lung cancer and reactivation of tuberculosis. In advanced cases, lung transplantation may be considered, and hence early referral to a specialist centre is encouraged. There is an urgent need for the development and implementation of systems to ensure that employees in at-risk occupations are not inhaling high levels of silica and that workers are regularly screened for the development of silicosis. ${ }^{2}$

\section{CASE CONTINUED}

The patient ceased working as a stonemason but continues to have severe exertional dyspnoea. He is now awaiting lung transplantation and has received workplace compensation.
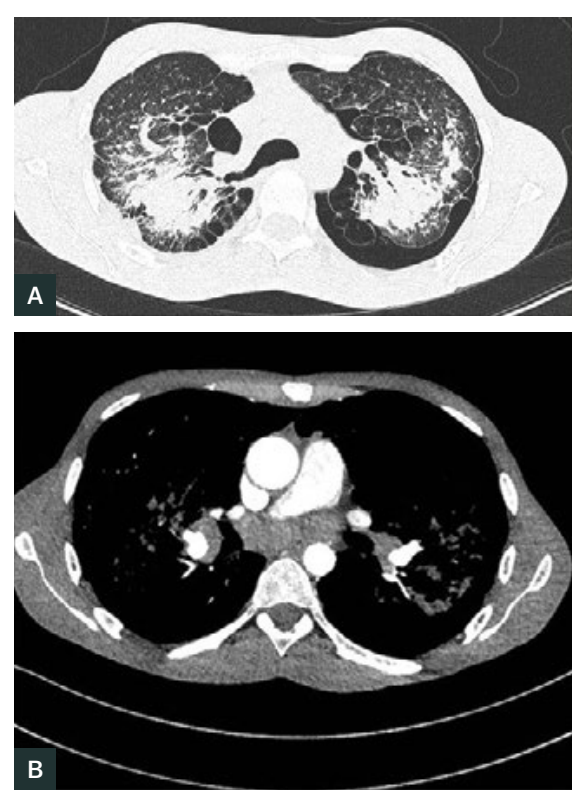

Figure 2. Axial computed tomography of the chest. Lung window (A) shows fibrotic change in the upper zones, upper lobe volume loss, extensive micro nodularity, bullae in both lung apices and a small-volume left-sided pneumothorax. The mediastinal window (B) identified bilateral hilar lymphadenopathy and subcarinal lymphadenopathy. Also identified were extensive micronodularity throughout both lungs, severe fibrotic change in the upper zones with superior displacement of the hila, marked volume loss in the upper lobes, compensatory hyperinflation of the lower lobes, confluent parenchymal opacification in the posterior aspect of both upper lobes and superior segments of the lower lobes. Biapical lung bullae together with a small to medium volume left-sided pneumothorax was noted.

\section{Key points}

- Occupational history is important when evaluating patients with chronic dyspnoea.

- Investigation of suspected ILD consists of HRCT of the chest, pulmonary function tests and laboratorial studies.

\section{Authors}

Sahan P Semasinghe Bandaralage MBBS, BSc, general medicine advanced trainee, Gold Coast University Hospital, Southport, Qld; Lecturer, School of Medicine, Griffith University, Southport, Qld. spbandara911@gmail.com

Krishna Bajee Sriram MBBS, FRACP, PhD, Staff Specialist - Respiratory Medicine, Department of Respiratory Medicine, Gold Coast University Hospital, Southport, Qld; Associate Professor, School of Medicine, Griffith University, Southport, Qld Competing interests: None.

Funding: None.

Provenance and peer review: Not commissioned, externally peer reviewed.

\section{References}

1. Hoy RF, Brims F. Occupational lung diseases in Australia. Med J Aust 2017;207(10):443-48.

2. Cowie RL, Becklake MR. 73 - Pneumoconioses. In: Broaddus VC, Mason RJ, Ernst JD, et al, editors. Murray \& Nadel's textbook of respiratory medicine. 6th edn. Philadelphia: WB Saunders, 2016; p. 1307-30.

3. Kramer MR, Blanc PD, Fireman E, et al. Artificial stone silicosis [corrected]: Disease resurgence among artificial stone workers. Chest 2012;142(2):419-24. doi: 10.1378/chest.11-1321.

4. Si S, Carey RN, Reid A, et al. The Australian work exposures study: Prevalence of occupational exposure to respirable crystalline silica. Ann Occup Hyg 2016;60(5):631-37. doi: 10.1093/ annhyg/mew007.

5. Rose C. Silicosis: Epidemiology. Waltham, MA: UpToDate, 2018. Available at www.uptodate.com/contents/ silicosis? topicRef $=4358 \&$ source=related_link [Accessed 2 October 2018].

6. Chen $W$, Liu $Y$, Wang $H$, et al. Long-term exposure to silica dust and risk of total and cause-specific mortality in Chinese workers: A cohort study. PLoS Med 2012;9(4):e1001206. doi: 10.1371/ journal.pmed.1001206. 